\title{
MATERIAL DE APOIO PARA O PROCESSO ENSINO/APRENDIZAGEM DE QUÍMICA EXPERIMENTAL PARA O ENSINO MÉDIO: ELABORAÇÃO, APLICAÇÃO E AVALIAÇÃO
}

\section{SUPPORTING MATERIAL FOR THE TEACHING/LEARNING PROCESS OF EXPERIMENTAL CHEMISTRY FOR HIGH SCHOOL: PREPARATION, IMPLEMENTATION AND EVALUATION}

\author{
Luciano Peres de Castro', Carlos Magno Rocha Ribeiro²
}

\begin{abstract}
${ }^{1}$ Instituto de Química, Programa de Pós-Graduação em Ensino de Ciências e da Natureza, Universidade Federal Fluminense, Campus do Valonguinho, Outeiro de São João Batista s/nº , Centro, Niterói, RJ, Brasil, CEP: 24020-141, proflucianoquimica@yahoo.com.br

${ }^{2}$ Instituto de Química, Programa de Pós-Graduação em Ensino de Ciências e da Natureza, Departamento de Química Orgânica, Universidade Federal Fluminense, Campus do Valonguinho, Outeiro de São João Batista s/nº , Centro, Niterói, RJ, Brasil, CEP: 24020-141, carlosmagnoribeiro@id.uff.br
\end{abstract}

\section{RESUMO}

Este trabalho descreve o percurso metodológico usado para a elaboração, aplicação e avaliação da produção de materiais de apoio aos professores e alunos dos três anos do Ensino Médio, os quais foram estudados em um Colégio Estadual de São Gonçalo (Rio de Janeiro), Brasil. Produziram-se 1 caderno de apoio ao professor e 3 cadernos de Experimentos de Química, contendo 50 experimentos, e 3 Cadernos de Conclusões para os alunos. Esses materiais visaram à motivação e facilitação do processo ensino/aprendizagem de Química usando a experimentação, investigação e a reflexão. Procurando conhecer a importância da elaboração desse material, realizou-se uma diagnose com 3 professores em 2012 e com 151 alunos dos $2^{-}$e $3^{0}$ anos do Ensino Médio em 2013, os quais consideraram importante e necessária a preparação desse tipo de recurso. Após elaboração, os materiais instrucionais foram aplicados e avaliados em 2013/2014, sendo considerados motivadores e facilitadores pela totalidade dos professores e pela grande maioria dos 227 alunos. Uma breve percepção da aprendizagem foi realizada, comparando-se o índice de aprovação de 221 alunos do ano de 2012 com 227 alunos do ano de 2013, além da análise das conclusões dos cadernos de conclusão dos alunos em 2013 e 2014. No primeiro caso, observou-se um aumento de cerca de $14 \%$ da aprovação dos alunos, enquanto no segundo percebeu-se uma melhoria na escrita e na retenção do conhecimento. Foi possível observar que a metodologia e os materiais de apoio empregados podem levar a um amadurecimento crítico reflexivo do alunado.

Palavras-chave: experimentação, investigação, material de apoio, ensino/aprendizagem, Química

\begin{abstract}
This paper describes the methodological approach used for the development, implementation and evaluation of the production of materials to support teachers and students in three years of high school, which were studied in the State College of São Gonçalo (Rio de Janeiro), Brazil. Were produced one book to the teacher and three books of Chemistry Experiments containing 50 experiments and three books Conclusion for the students. These materials aimed at the motivation and facilitation of teaching/learning using chemistry experimentation, research and reflection. Seeking to
\end{abstract}


know the importance of developing this material was held a diagnosis with 3 teachers in 2012 and 151 students of the second and third years of high school in 2013, which considered important and necessary the preparation of this type of resource. After the preparation of instructional materials, they were applied and evaluated in 2013/2014, in which were considered motivators and facilitators for all the teachers and the vast majority of the 227 students. A brief perception of learning was performed by comparing the 221 students of the year approval rating of 2012 with 227 students in the year 2013, in addition to the analysis of the conclusions of the students' completion books in 2013 and 2014. In the first case observed an increase of about $14 \%$ of the approval of the students, while in the second case it was noticed an improvement in writing and knowledge retention. It was observed that the methodology and support materials used can lead to a reflexive critical maturity of the students.

Key words: experimentation, investigation, supporting material, teaching/learning, Chemistry

\section{INTRODUÇÃO}

Os Parâmetros Curriculares Nacionais (PCN) apresentam-se como um facilitador da transformação de objetivos, conteúdos e didática para os ensinos Fundamental e Médio do Brasil. Em relação ao Ensino de Química (EQ), algumas recomendações dos PCN podem ser consideradas não somente no exercício da profissão do educador, mas também na preparação do material didático-pedagógico (BRASIL, 2002, p. 239). Para o conteúdo de Química a ser abordado nas escolas, pode-se ressaltar a importância: a) da visão crítica da ciência, uma vez que os conhecimentos não devem ser apresentados de forma isolada, prontos e acabados; b) da História da Química como parte da produção do conhecimento; c) no desenvolvimento do educando como pessoa humana e como cidadão, através de adequação da organização dos conteúdos químicos e da metodologia empregada, na busca da capacitação dos educandos a tomarem suas próprias decisões (BRASIL, 2002).

Conforme os PCN, por exemplo, as atividades experimentais na escola do Ensino Médio (EM) devem por sua vez considerar a sua função pedagógica, e não aquela procurada pelo cientista, entretanto devem favorecer o desenvolvimento do conhecimento matemático, científico e tecnológico de forma cidadã e não para a formação de especialistas. Desse modo, deve-se buscar no EM as competências, habilidades e disposições de condutas e não a quantidade de informação. Deve-se estimular o "aprender" e o "pensar", para que haja um significado no que se aprende ao correlacionar teoria e prática, ao fundamentar a crítica por meio de uma argumentação 
baseada em fatos e sentimentos que a aprendizagem desperta (BRASIL, 2002). Tais pressupostos estão de acordo com a proposta da LDB 9394, capítulo $\mathrm{n}^{\mathrm{o}} 35$, que diz que o EM deverá desenvolver "a autonomia intelectual e pensamento crítico". Assim, o EQ deve procurar capacitar os alunos a decidirem por si só a como agir em situações problemáticas, contribuindo assim para seu desenvolvimento humano e cidadão (BRASIL, 2002, p. 241). Logo, tem-se a ideia de que a conquista da cidadania está associada à capacidade de se posicionar de maneira crítica, responsável e construtiva.

Os PCN voltados ao Ensino Médio, assim como Moreira (MOREIRA, 2000), apontam que o EQ pode ser um instrumento de formação humana se promovido como um meio de interpretar o mundo e intervir nele, através dos conceitos, métodos e linguagens próprios.

Educadores na área de Química têm demonstrado ao longo dos anos que o aprendizado pode se tornar mais eficiente se for usada a multimídia em jogos, laboratórios virtuais, animações computacionais, assim como filmes, jornais, revistas em quadrinhos, improvisações teatrais, bem como na experimentação.

Em relação à experimentação em Química, pode-se dizer que ela pode priorizar o contato dos alunos com os fenômenos químicos, possibilitar aos alunos criar modelos, permitir ao professor ocupar um lugar estratégico no que é cientificamente aceito e dialogável com a comunidade científica, problematizar temas socialmente relevantes (GIORDAM, 1999), privilegiar o caráter investigativo (FARIAS; BASAGLIA; ZIMMERMANN, 2009), estimular o desenvolvimento conceitual, permitir que o estudante explore suas habilidades cognitivas (SUART; MARCONDES; LAMAS, 2010), promover uma alfabetização científica (CHASSOT, 2003) e formar um cidadão crítico (SANTOS; SCHNETZIER, 1996), o que está de comum acordo com Art. 35 inciso III da LDB 9394/96 (BRASIL, 1996).

Segundo Giordam (1999, p.43), a experimentação desperta interesse, motiva e envolve o alunado, pois eles a consideram como algo lúdico. Entretanto, a experimentação deve fazer com que o aluno reflita entre questões que envolvam a prática e a teoria, que procure um ensino contextualizado, investigativo e que permita ao aluno a formulação de hipóteses, questionamentos e discussão dos fenômenos apresentados (MACHADO; MÓL, 2008, p. 58). A experimentação deve favorecer a reconstrução do conhecimento e possibilitar ao aluno criar seus modelos explicativos 
sobre teorias com sua própria linguagem, o que favoreceria uma análise crítica da aplicação do saber químico em prol da sociedade (MALDANER, 2003, p. 57).

Conforme Guimarães (2009, p. 198) e Oliveira et alii (2010, p. 101), quando a metodologia é pautada em experimentos do tipo "receita de bolo", os alunos recebem o roteiro para seguir e obtém os resultados esperados pelo professor, não levando então ao raciocínio e questionamento. Além disso, muitas vezes estão enraizadas em teorias empiristas-indutivistas, que buscam na formação do educando uma espécie de minicientistas.

Outro fator importante a ser considerado na experimentação em Química são os objetivos procurados pelos professores para esse tipo de atividade, que devem buscar segundo Santos a motivação dos alunos; o domínio de técnica de laboratório; a aprendizagem de conceitos científicos; o conhecer e utilizar o método científico e o desenvolvimento de atitudes científicas (SANTOS JR; MARCONDES, 2010, p. 4).

Santos e Schnetzier (1996, p. 29) concluem que a experimentação deve promover a habilidade investigativa da ciência e, como lembra Oliveira et alii (OLIVEIRA; HARTWIG; FERREIRA, 2010, p. 101), além da habilidade investigativa “outras habilidades deverão ser proporcionadas como a manipulação e a comunicação".

Francisco Jr et alii (2008, p. 34-41) propõem que a experimentação seja problematizadora e baseada nas perspectivas de Paulo Freire. Nessa abordagem, tendo como princípio o conhecimento prévio do aluno que se encontra inacabado e incompleto, são propostas três momentos pedagógicos: problematização inicial, organização do conhecimento e aplicação do conhecimento.

Apesar de ser consenso sobre a importância do uso da experimentação, inserir atividades experimentais nas aulas de Química não é uma atividade comum e simples no EM. Segundo Maldaner (2003), a falta de utilização desse recurso deve-se a vários fatores como: troca de professor, laboratório em reforma, impedimento do professor, carência de pessoal técnico, condições para a realização de atividades experimentais e falta de laboratório. Para Santos Júnior e Marcondes (2010, p. 3), diversos fatores dificultam a implementação de atividades experimentais nas escolas, como, por exemplo, a falta de materiais para a realização das atividades práticas, a falta de estrutura escolar, o despreparo dos docentes, excesso de alunos nas salas e poucas aulas de Química na grade curricular. 


\section{Ensino, Saúde e Ambiente - V9 (2), pp. 63-93, Ago. 2016}

O livro didático e/ou apostila é outro gênero didático-pedagógico utilizado no processo de ensino-aprendizagem. Câmara (2012, p. 3) acredita que tanto o livro didático como a apostila já estão inseridos no meio escolar e isso lhe confere certa autoridade, o que leva ao desenvolvimento de um papel de senhor do pensamento na constituição do sujeito.

Lajolo e Zilberman (1996, p. 121) dizem que o livro didático tem influência e são inevitáveis e encontrados nas diversas fases de formação escolar de uma pessoa, podendo ser, por exemplo, uma cartilha, seleta ou manual. Do mesmo modo, Pacheco e Coelho (2012, p. 3) consideram que o uso do material impresso é inevitável.

Em relação ao livro didático no processo científico-pedagógico, Lopes comenta que Bachelard reserva ao livro espaço fundamental, pois o livro, na medida em que veicula a ciência para os cientistas, possui papel determinante na construção do conhecimento científico e na manutenção dos cientistas na escola. O pensamento científico é um livro ativo, um livro que ao mesmo tempo é audacioso e prudente, um livro que se desejaria apresentar uma nova edição, uma edição melhorada, reorganizada, ou seja, em vias de crescimento. Contrário ao pensamento científico é o livro escolar, uma obra fechada, prevalecendo a não reformulação, não podendo ser lido sem que se obedeça a ordem dos capítulos, reforçando todos os males do dogmatismo (LOPES, 1993). Segundo Abreu (ABREU, 2011, p. 31), Bachelard faz severas críticas à forma como alguns livros são escritos, pois, segundo ele, não possuem como ponto de partida a natureza e a vida cotidiana.

A crítica ao apostilamento, segundo Lima (2006, p. 1), "não deve ser dirigida ao uso eventual de apostilas artesanalmente elaboradas pelo professor ou por sua escola, mas sim, à pressão da ideologia do mercado que faz da apostila um método único de saber e de poder". Sendo assim, uma apostila/material de apoio, elaborada pelo professor com atividades lúdicas e/ou experimentais que proporcionem a autonomia intelectual e o pensamento crítico do aluno pode contribuir não só para a melhoria do ensino-aprendizagem como para a formação do cidadão.

Considerando que a experimentação no EQ também pode colaborar na formação do educando como cidadão, proporcionando um conhecimento útil para a vida, o trabalho, a tomada de decisões e para a sua participação ativa na sociedade, novos trabalhos que promovam o uso da experimentação na escola devem ser 
estimulados. Ressaltamos que as aulas experimentais, algo novo na vida do educando, com essas formas de "pensar o ensino" podem, por exemplo, ser aplicadas de forma problematizadora ou investigativa na elaboração de cadernos de experimentos de Química que podem ter um questionário introdutório que sirva como um organizador prévio no processo de ensino-aprendizagem do alunado, formando assim subsunçores no educando que estimulem o professor e o aluno a usarem essa forma pedagógica.

Os experimentos nesses materiais de apoio devem ser descritos de forma que o aluno, durante a experimentação, possa ter um espírito investigativo ou problematizador e o início de uma formação crítica/reflexiva, propiciando que o professor abandone a narrativa simples e direta para que ele e o aluno exerçam uma postura dialógica, sendo aprendizes entre pares, isto é, tornando o ensino socialmente ativo.

Acreditamos também que um caderno de experimentos deva ter um espaço de conclusão prévia de cada experimento, onde o aluno possa desenvolver, após a atividade prática, a investigação de suas conclusões iniciais, ou seja, a aprendizagem crítica de suas primeiras conclusões, questionando-a e conciliando-a a novas informações, avançando, desta forma, o pensamento científico.

Assim, para que esses pressupostos sejam colocados em prática, a existência de um caderno de conclusões do aluno pode ser interessante no processo de ensinoaprendizagem, caso apresentem orientações prévias para que haja um avanço no pensamento científico na direção da maior complexidade racional (MOREIRA; MASSONI, 2009, p. 27), ou seja, que busque um perfil epistemológico onde um conceito possa ser confrontado com a cultura pessoal, tornando-o mais abrangente. É justamente no caderno de conclusão que o professor poderia observar não somente o avanço do pensamento científico do aluno como também os erros cometidos, retificando-os para favorecer o seu aprendizado.

Além desses materiais de apoio, seria muito útil a elaboração de cadernos de apoio ao professor, que pudessem trazer orientações que venham a ser utilizadas em todos os anos do EM para o desenvolvimento de práticas investigativas e organizacionais, pois poderia motivar e facilitar ao professor a utilização da experimentação em sua prática docente.

Desse modo, o presente trabalho descreve o percurso metodológico para a elaboração, aplicação e avaliação, e seus desdobramentos, de materiais de apoio ao 
professor (1 volume), cadernos de experimentos (3 volumes) e conclusão (3 volumes) para serem usados pelos alunos do Ensino Médio.

\section{PERCURSO METODOLÓGICO}

Este estudo pode ser classificado como uma Pesquisa Aplicada quanto à sua Natureza, pois busca a melhoria do ensino-aprendizagem de Química ao usar o laboratório de Química como alternativa pedagógica à qual é usada atualmente. Segundo Kauark, Manhães e Medeiros (2010, p. 26), a Pesquisa Aplicada tem o objetivo de "gerar conhecimentos para aplicação prática, dirigida à solução de problemas específicos. Envolve verdades e interesses locais". É uma Pesquisa Exploratória quanto ao objetivo, pois procura identificar os fatores que podem contribuir ou agir para a melhoria do EQ. Em relação aos procedimentos, podemos dizer que é uma Pesquisa-Ação, uma vez que por definição “objetiva a maior familiaridade com o problema, tornando-o explícito, ou a construção de hipóteses. Envolve levantamento bibliográfico; entrevista com pessoas que tiveram experiência prática com o problema pesquisado; análise de exemplos que estimulem a compreensão", e procura reformular o material de apoio a partir dessas informações. Porém, pode ainda ser considerada uma Pesquisa Ex-Post-Facto, pois durante as atividades experimentais, os referenciais da Aprendizagem Significativa Crítica de Moreira e da Epistemologia de Bachelard objetivam a melhoria do ensino-aprendizado de Química de um sistema educacional, que é a Escola.

A metodologia utilizada neste trabalho baseou-se em seis momentos:

O primeiro momento foi o da elaboração e aplicação de questionários diagnósticos com professores e alunos de um Colégio Estadual da cidade de São Gonçalo no estado do Rio de Janeiro. A primeira diagnose foi planejada para ser realizada inicialmente com os professores para observar a importância e a necessidade de se conhecer a opinião deles sobre o uso do laboratório da escola e sua importância, e seria aplicado em 2012, ano de início desse trabalho, a professores de Química do horário diurno do Colégio. O questionário teria cerca de seis perguntas, sendo cinco delas objetivas e uma que teria opções numéricas distribuídas de acordo com o grau de dificuldade. As perguntas deveriam tratar sobre o uso geral de novos recursos no processo ensino-aprendizado segundo a visão didática-pedagógica do professor e do uso 


\section{Ensino, Saúde e Ambiente - V9 (2), pp. 63-93, Ago. 2016}

do laboratório de Química no colégio. Também deveria ocorrer uma diagnose no início de 2013 com os alunos do $2^{\circ}$ e $3^{0}$ anos do horário da manhã, após observarmos a opinião dos professores. As turmas do $1^{\circ}$ ano não participariam da diagnose porque praticamente todos os alunos são novos e não conhecem ainda a escola. A diagnose teria cinco perguntas objetivas sendo que em uma existiria uma opção discursiva, também buscando observar a opinião dos alunos sobre a importância de um laboratório e materiais de apoio.

No segundo momento, seria realizado um estudo teórico e epistemológico para a elaboração de materiais de apoio ao professor para a utilização do laboratório, considerando o artigo 35 da LDB 9394/96 (BRASIL, 1996) e os PCN (BRASIL, 2002), e o levantamento e adaptação de experimentos que atendessem às necessidades do Currículo Mínimo de Química. A preparação dos materiais de apoio buscaria respeitar:

1) a clareza no que se refere aos períodos pré e pós-atividade, visando à construção de conceitos, o qual não deve ser desvinculado da teoria e laboratório, tendo em vista que a experimentação formal não soluciona o problema do ensino aprendizagem, como mostram os PCN (BRASIL, 2002, p. 247);

2) uma aprendizagem significativa crítica baseadas nas seguintes premissas, conforme discute Moreira (2000, p. 20, 21): a) a importância em estimular o questionamento ao invés de respostas prontas; b) a diversidade de materiais educativos; c) a aprendizagem pelo erro, pois é normal errar e aprende-se corrigindo os erros; d) o aluno como perceptor e representador do mundo; e) a consciência semântica em que o significado está nas pessoas e não nas palavras; f) a incerteza do conhecimento e sua evolução; g) que a desaprendizagem do conhecimento prévio funciona como obstáculo epistemológico; h) conhecimento como linguagem; e i) a diversidade de estratégias e abandono da lousa e quadro escolar;

3) a filosofia do não de Bachelard, que não significa uma atitude de recusa e sim uma atitude de conciliação (MOREIRA; MASSONI, 2009, p. 27) e a busca pela convivência positiva com o diferente, o que promoveria a aceitação do dissenso (LOPES, 1996, p. 267). Com relação à experimentação, segundo Lopes (LOPES, 1993), Bachelard defende que ela não deverá ter o cunho pitoresco, espetacular, belo, mas favorecer o esforço intelectual para o racionalismo, pois aprender ciência não é permitir que a mente permaneça no concreto, e sim abstraia, analise e tenha o prazer gerado pelo mérito de se 
vencer as dificuldades do saber. Desse modo, as escolhas de atividades de laboratório priorizariam: a) experimentos simples e seguros (MACHADO; MOL, 2008a, p. 58); b) que as experiências não fossem muito marcantes, cheias de imagem, pois podem ser falsos centros de interesse (ABREU, 2011, p.50); c) a baixa atividade poluidora, evitando o uso de substâncias de elevada toxicidade, como benzeno, tolueno, clorofórmio, formaldeído, tetracloreto de carbono e sais contendo íons mercúrio, chumbo, cromo, cádmio, níquel, bário, arsênio, ósmio, cianetos, e d) o uso de equipamentos de proteção coletiva e individual como extintor de incêndio, caixa de primeiros socorros, chuveiro, uso obrigatório de jaleco (avental), luva e óculos de proteção (MACHADO; MOL, 2008b, p. 39).

A terceira parte da metodologia envolveu a elaboração de um caderno de apoio ao professor, três cadernos de experimentos para o aluno e três cadernos de conclusão do aluno. O caderno do professor deveria facilitar ao professor a preparação de atividades didáticas usando os experimentos. Os volumes de experimentos deveriam conter práticas laboratoriais de Química para os três anos do EM do Colégio, enquanto os cadernos de conclusão de prática de laboratório buscariam estimular o desenvolvimento investigativo e crítico do aluno.

Assim, no caderno de apoio ao professor existiriam orientações gerais que conduzissem à preparação pelo professor de atividades experimentais para serem utilizadas em todos os anos do EM, e alguns comentários sobre o conteúdo de cada experimento na busca da facilitação de discussões em sala de aula.

Além do caderno do professor, os cadernos para os alunos conteriam atividades experimentais testadas anteriormente para serem distribuídas de acordo com o conteúdo do Currículo Mínimo de Química do Estado do Rio de Janeiro para todos os três anos do EM (RIO DE JANEIRO, 2012). Sendo assim, seriam elaborados três cadernos de atividades experimentais e três cadernos de conclusão.

Os cadernos de experimentos dos alunos, distribuídos em três volumes, deveriam conter seções que possuíssem distintas funções que convergissem na busca da aprendizagem significativa crítica e investigativa e teriam quatro temas/conteúdos distintos que estão diretamente relacionados com os conceitos abordados nos quatro bimestres. Cada tópico possuiria uma introdução que interligasse o cotidiano discente com as atividades experimentais. Dentro desses temas existiriam três momentos 


\section{Ensino, Saúde e Ambiente - V9 (2), pp. 63-93, Ago. 2016}

baseados nos aportes teóricos da aprendizagem significativa crítica de Moreira (2000) e epistemológicos de Bachelard (LOPES, 1993): Pensando, Agindo e Concluindo.

O caderno de conclusão do aluno, a princípio, teria uma parte inicial com o objetivo de observar se o aluno desenvolveria habilidades cognitivas, elaboraria hipóteses, anotaria e analisaria os dados experimentais, para promover a alfabetização científica; e uma parte posterior para desenvolver, se necessário, o princípio da aprendizagem pelo erro e da desaprendizagem através do intercâmbio das ideias.

O quarto momento trataria da aplicação dos materiais de apoio elaborados para as aulas experimentais nos três anos do EM. A aplicação desses materiais iniciar-se-ia no ano 2013 e deveria contar com a participação de professores da escola e se possível de alunos do Programa de Bolsas de iniciação à Docência da Universidade Federal Fluminense (PIBID-UFF). Todos os participantes receberiam orientações prévias da função que deveriam exercer no momento das atividades práticas, considerando as orientações da aprendizagem significativa crítica. As atividades experimentais realizadas com os alunos seriam distribuídas em turmas do EM, sendo duas do primeiro ano, uma do segundo e três do terceiro. Os alunos deveriam ser organizados em duplas espontaneamente escolhidas entre eles, porém poderia haver turmas com a formação de trios, caso houvesse número ímpar de alunos.

A quinta parte do trabalho trataria da avaliação do material de apoio (caderno de experimentos e de conclusão do aluno) e da infraestrutura do laboratório, que poderia ser realizada no final de 2013 junto aos alunos e professores buscando conhecer as suas motivações de ensino-aprendizagem, bem como avaliação dos produtos de apoio desenvolvidos e a infraestrutura. Após conhecer a opinião dos alunos e professores em 2013, os materiais poderiam ser reformulados para serem aplicados em 2014 e posteriormente avaliados pelos professores de Química.

O questionário avaliativo conteria perguntas que tratassem da avaliação do caderno de experimento do aluno, do caderno de conclusão do aluno e do caderno do professor. As três primeiras perguntas dividir-se-iam em subperguntas de natureza objetiva e na quarta o professor poderia discursar com comentários e sugestões. $\mathrm{O}$ questionário deveria apresentar perguntas-chaves que se dividiriam em subperguntas de diferentes naturezas com opções objetivas. Da primeira a terceira pergunta haveria duas subperguntas de natureza discursiva em que o entrevistado poderia fazer comentários ou 


\section{Ensino, Saúde e Ambiente - V9 (2), pp. 63-93, Ago. 2016}

dar sugestões. Na terceira pergunta para as turmas do $2^{\circ}$ e $3^{\circ}$ anos haveria um acréscimo de duas subperguntas que tratassem da confecção das atividades artesanais. Na sexta pergunta, para as turmas do terceiro ano, existiriam subperguntas sobressalentes atribuídas ao vestibular.

Finalmente, no sexto momento, uma percepção do aprendizado pela análise das conclusões das atividades experimentais obtidas a partir do caderno de conclusão dos alunos nos anos de 2013 e 2014, e pela análise da comparação entre os índices de aprovação dos anos de 2012 e 2013, anos em que se não se usaria o material preparado e aquele em que ele seria aplicado, respectivamente.

\section{RESULTADOS E DISCUSSÃO}

Após os estudos iniciais relacionados ao trabalho, elaborou-se o questionário diagnóstico para os professores com as perguntas mostradas na Figura 1. A diagnose foi realizada nos dias 23 e 25 de outubro de 2012 com 3 professores de Química do horário diurno do Colégio.

Figura 1: Perguntas do questionário diagnóstico dos professores.

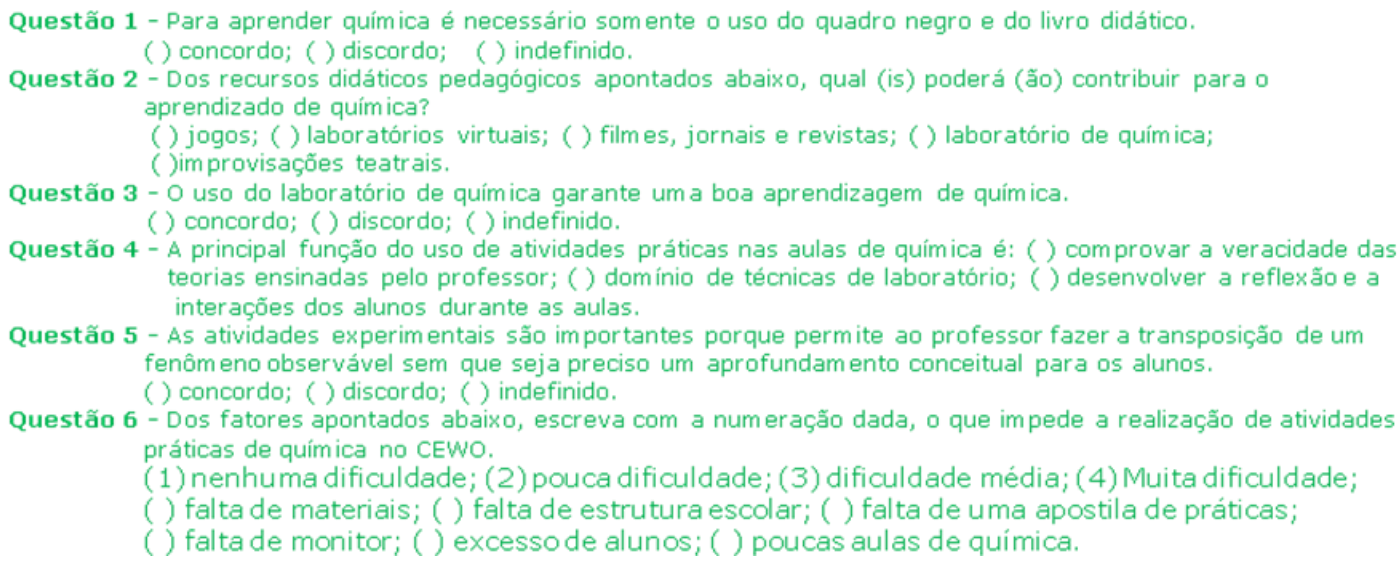

\section{Fonte: Luciano Peres de Castro.}

O objetivo da pergunta 1 era identificar se os professores estariam propensos ao uso de novos recursos além do tradicional quadro negro e livro didático. A totalidade dos professores (100\%) marcaram a opção discordo, confirmando que a utilização de novas alternativas poderia ser adotada pelos professores de Química para despertar o interesse do aluno pela ciência proporcionando a melhoria do ensino e aprendizagem no colégio. 


\section{Ensino, Saúde e Ambiente - V9 (2), pp. 63-93, Ago. 2016}

A pergunta 2 teve o objetivo de apontar quais recursos seriam considerados primordiais pelos professores para a melhoria do aprendizado de Química. A totalidade (100\%) dos professores assinalou a opção laboratório de Química, porém um deles também escolheu filmes, jornais e revistas, transparecendo que ele está mais disponível a usar alternativas lúdicas além do laboratório de Química, o que é um fator positivo, visto que a inserção de novas atividades no âmbito escolar constitui-se uma metodologia diferenciada que vem crescendo segundo pesquisas nos últimos anos apontadas pela SBQ e os Encontros Nacionais no EQ. Lembramos, porém, que especialistas em didática das ciências com frequência fazem críticas ao trabalho com experimentação quando se destinam apenas a ilustrar ou comprovar teorias anteriormente estudadas, tendo em vista que são limitadas e não favorecem a construção de conhecimento pelo aluno (BUENO; KOVALICZN, 2009, p. 2).

As perguntas 3, 4 e 5 do questionário diagnóstico do professor foram baseadas no trabalho realizado por Santos e Marcondes (2010, p. 6). A pergunta de número 3 buscou saber se os professores do Colégio acreditavam que a experimentação seria essencial no ensino, garantindo a aprendizagem de Química. Novamente $100 \%$ dos professores marcaram a opção concordo, mostrando que têm uma visão baseada na racionalidade técnica, presos ao academismo tradicional, enraizadas em teorias empiristas indutivistas. Estudos apontam que a experimentação no EM deve desenvolver a reflexão, o questionamento, ampliando a cognição dos alunos acerca dos conteúdos estudados (SANTOS; MARCONDES, 2010, p. 7; GUIMARÃES, 2009; MACHADO; MÓL, 2008, p. 57).

Das três opções destinadas a pergunta 4, somente a terceira opção valida o uso da experimentação no EM. A primeira traduz que a experimentação está alinhada à natureza demonstrativa, trazendo a concepção de que a Ciência é constituída de verdades absolutas. A segunda valoriza mais o domínio do conhecimento técnico do que a didática do ensino. $\mathrm{O}$ resultado expôs que somente um professor marcou a terceira opção e os demais, a primeira. Portanto, se forem desenvolvidas atividades experimentais no colégio, os professores necessitarão de um material de apoio que revele o real uso da experimentação. A pergunta 5 valoriza a autossuficiência da atividade experimental e compartilha da concepção de que a experimentação não precisa de um aprofundamento conceitual, o que é preocupante, pois é preciso integrar atividades práticas com discussão e interpretação de dados para o desenvolvimento cognitivo e conceitual dos alunos. Os três professores marcaram a primeira opção, o que 


\section{Ensino, Saúde e Ambiente - V9 (2), pp. 63-93, Ago. 2016}

consolida com a ideia da perpetuação da racionalidade técnica nas práticas pedagógicas, da necessidade de ruptura desse paradigma e elaboração de um manual explicativo que facilite ao professor a preparação de atividades didáticas usando os experimentos baseadas nesses pressupostos.

Após observar as concepções pedagógicas, os recursos didáticos e o consenso quanto à realização de atividades laboratoriais através das questões anteriores, buscouse com a sexta pergunta levantar os principais obstáculos que poderiam impedir a realização de práticas no colégio. O resultado das respostas dessa questão é representado na Gráfico 1.

Gráfico 1 - Principais obstáculos para a experimentação

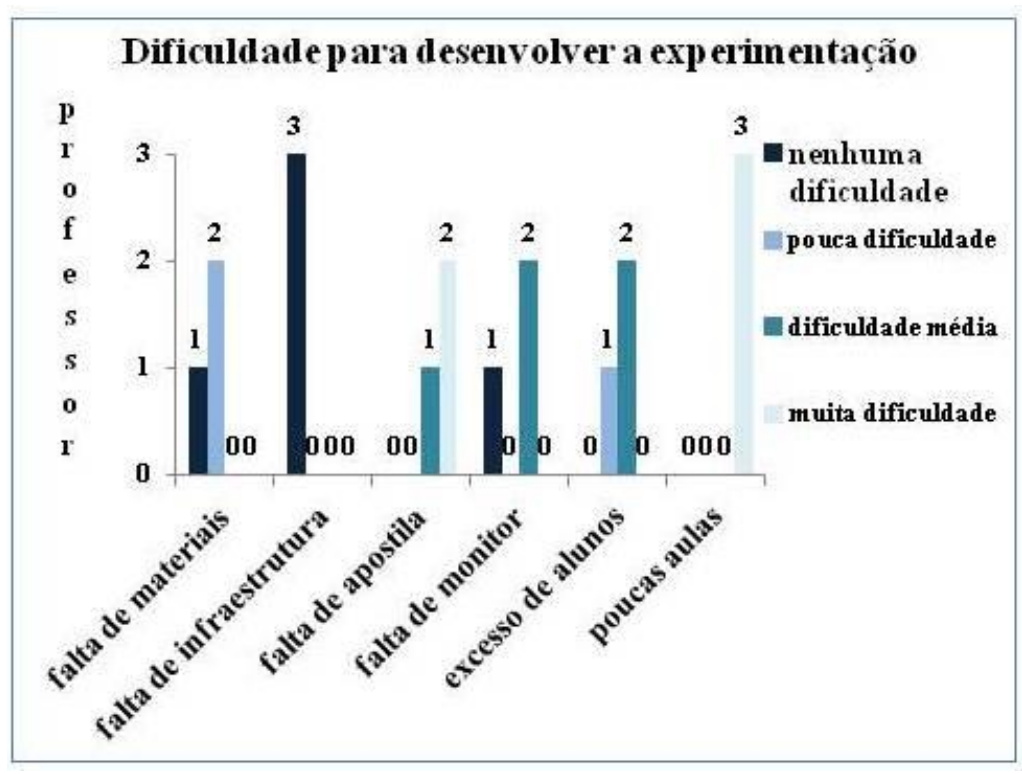

Fonte: Luciano Peres de Castro

A diagnose com os professores mostrou que a falta de materiais e a falta de estrutura não são os problemas para o uso do laboratório, apesar do número de docentes pesquisados ser pequeno. Contudo, a maior dificuldade apontada pelos professores, justificando a pouca utilização de atividades experimentais, foram: o número de aulas de Química seguido pela falta de apostila de práticas, excesso de alunos e falta de um monitor. Portanto, tornar viável o uso do laboratório baseado nos pressupostos da formação da cidadania, da reflexão crítica sobre o mundo, do aprimoramento da cognição do educando, do estabelecimento da relação entre teoria e prática, do espírito investigativo, da alfabetização científica dentre outras questões, no colégio, requer estratégias que supram as dificuldades apontadas pelos professores. $\mathrm{O}$ número de aulas de Química e o excesso de alunos é algo que está acima dos limites do docente, cabendo 


\section{Ensino, Saúde e Ambiente - V9 (2), pp. 63-93, Ago. 2016}

à Secretaria Estadual de Educação a solução desse problema. Entretanto, caso haja um material de apoio experimental, parte dos experimentos poderiam ser introduzidos pelo professor durante as aulas conceituais usando-os de uma forma investigativa, e a outra parte seria realizada pelos alunos nas aulas experimentais no laboratório, o que iria provavelmente atenuar a demanda do número de aulas de Química. Com relação à carência do monitor, ela poderá ser suprida se o professor escolher para cada ano que for lecionar dois alunos e orientá-los, antecipadamente, à prática, provocando motivação e interesse dos educandos. Para a falta de material de apoio experimental, seria interessante elaborar dois manuais: o de experimentos que apoie o professor a desenvolver práticas laboratoriais e o explicativo que facilite o professor na preparação de atividades didáticas usando os experimentos.

A diagnose sobre o mesmo tema com os alunos foi composta de 5 perguntas (Figura 2) e realizada nos dias 19 e 21 de março de 2013 com 151 alunos do horário da manhã, sendo 38 alunos do segundo ano e 113 do terceiro ano do EM do Colégio. As turmas do primeiro ano não participaram da diagnose porque praticamente todos os alunos eram novos e não conheciam ainda a escola.

Figura 2: Perguntas do questionário diagnóstico dos alunos

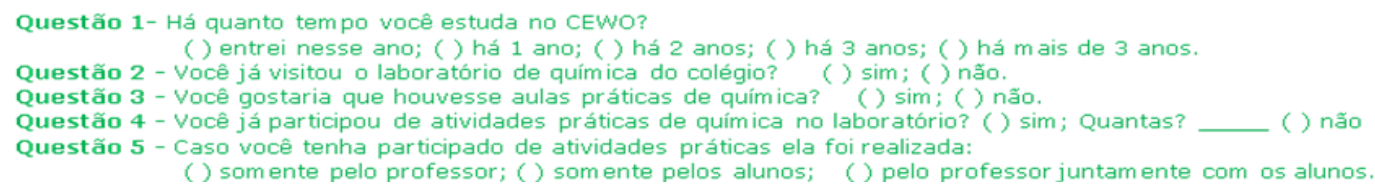

\section{Fonte: Luciano Peres de Castro}

$\mathrm{Na}$ pergunta 1 buscou-se obter dados que permitam confrontá-los com a segunda e quarta pergunta que tratam do uso do laboratório de Química durante os anos de atividade escolar dos alunos no Colégio. Os resultados obtidos para a turma do segundo ano foram que $8 \%$ dos alunos eram novos e $92 \%$ estudavam há pelo menos um ano no colégio. No terceiro ano, verificou-se que 3\% dos alunos eram novos, 9\% estudavam há dois anos no colégio, $75 \%$ há três anos e 13\% há mais de três anos.

A pergunta 2 teve a função de verificar se os alunos antigos conhecem o interior do laboratório de Química através de uma visitação. As respostas encontradas no segundo ano foram: $78 \%$ responderam sim, $22 \%$ não (8\% de alunos novos e $14 \%$ de alunos antigos). Conclui-se que o número de alunos antigos que não conhecem o interior do laboratório do colégio para o segundo ano é de cerca de $15 \%$ desse valor. 


\section{Ensino, Saúde e Ambiente - V9 (2), pp. 63-93, Ago. 2016}

Os resultados encontrados para o terceiro ano foram: $88 \%$ responderam sim, $12 \%$ não, sendo desta quantidade $3 \%$ de alunos novos e $9 \%$ de alunos antigos. Concluise, portanto, que o número de alunos deste ano que não conhecem o laboratório é relevante, pois em dois anos não tiveram nenhum tipo de atividade nesse local.

A $3^{\mathrm{a}}$ pergunta buscava confrontar o resultado obtido com as pesquisas no EQ que trata do consenso dos alunos quanto ao uso da experimentação no EM. O resultado obtido foi que $100 \%$ dos alunos gostariam que houvesse aulas experimentais de Química no decorrer do seu EM o que corrobora com as pesquisas que tratam desse assunto que atribuem à experimentação "um caráter motivador, lúdico, essencialmente vinculado aos sentidos" (GIORDAN, 1999, p.43).

O objetivo da pergunta 4 foi apurar o uso do laboratório em atividades práticas. $\mathrm{O}$ resultados obtidos para o $2^{\underline{0}}$ e $3^{\underline{o}}$ ano são apresentados no Gráfico 2.

\section{Gráfico 2 - Quantidade de aulas práticas que os alunos já tiveram}

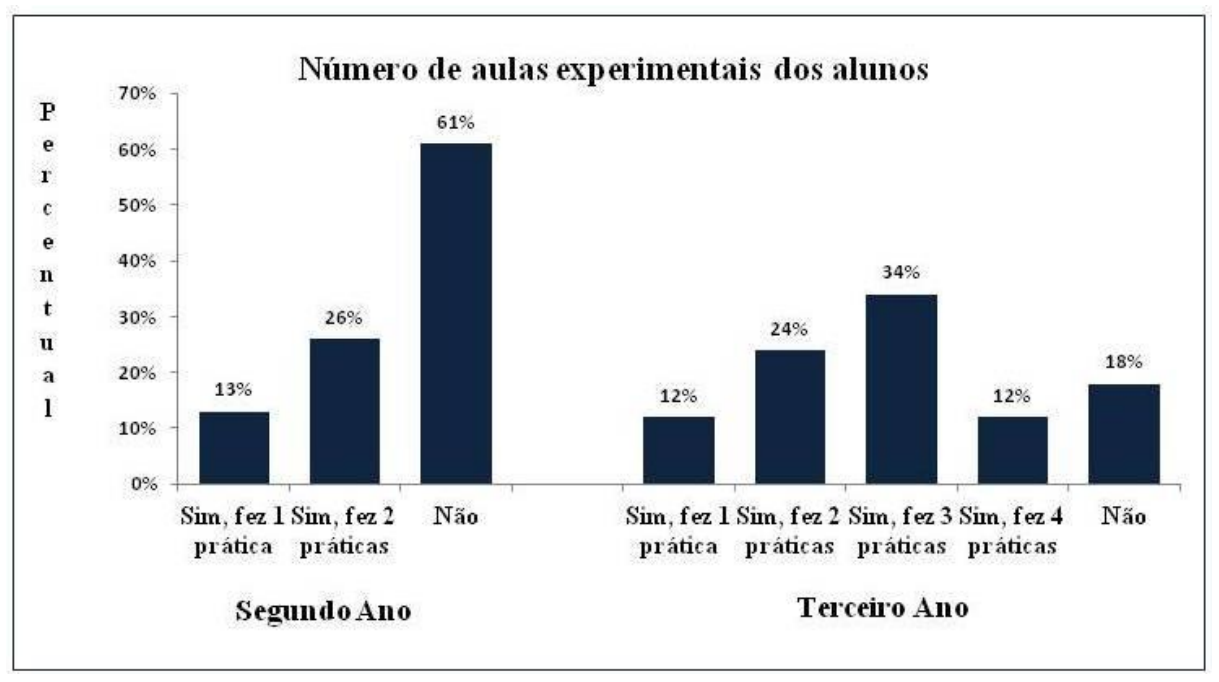

Fonte: Luciano Peres de Castro.

As respostas para essa Questão mostraram que as atividades laboratoriais foram pouco utilizadas no $2^{\circ}$ ano, a saber: $39 \%$ responderam sim, $61 \%$ não, sendo desta quantidade $8 \%$ de alunos novos e $53 \%$ de alunos antigos. Confrontando os dados da segunda pergunta para esses alunos com a quarta, observa-se que dos $78 \%$ deles visitaram o laboratório e metade fez atividade laboratorial. Outro fator a ser considerado é o número pequeno de práticas realizadas, o que pode ser corroborado pela falta de um material de apoio a essas atividades. Nesse caso, percebe-se um avanço quanto ao uso do laboratório. Ao confrontar as respostas da segunda com a quarta pergunta, observa-se que, dos $88 \%$ dos alunos que visitaram o laboratório, $82 \%$ fizeram 
atividades laboratoriais. Todavia, apesar do saldo positivo com relação ao uso do laboratório, ao diagnosticar na primeira pergunta que $92 \%$ desses alunos estudavam há pelo menos dois anos na escola, conclui-se que o número de práticas realizadas no decorrer da vida estudantil foi pequeno, o que ratifica os obstáculos apresentados pelos professores quanto ao número reduzido de aulas experimentais de Química, a falta de um caderno de práticas, o excesso de alunos e a falta de um monitor.

A pergunta 5 teve a finalidade de verificar como está sendo realizada a experimentação, visto que na diagnose realizada com os professores os resultados apontaram que os docentes possuem concepções empiristas cercadas por uma racionalidade técnica, desenvolvendo a experimentação com natureza demonstrativa. As três opções mostrariam o quanto os alunos estão engajados no manusear da atividade experimental, na geração de problematização, discussão e questionamentos. Os resultados obtidos para o $2^{\underline{0}}$ e $3^{\circ}$ ano são apresentados no Gráfico 3.

\section{Gráfico 3 - Tipos de atividades práticas realizadas nos diferentes anos}

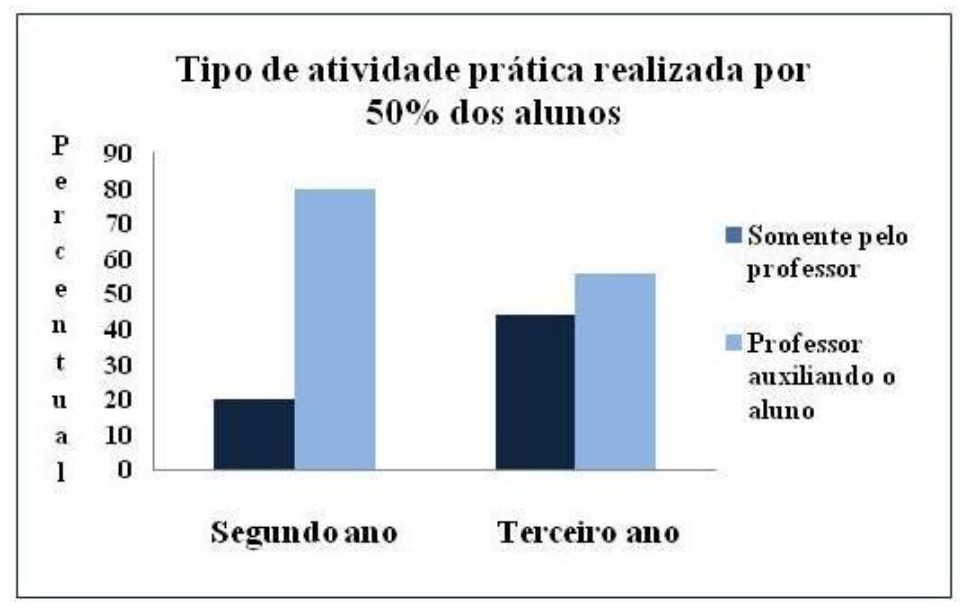

Fonte: Luciano Peres de Castro.

Nota-se que as atividades experimentais desenvolvidas com o $3^{\mathrm{o}}$ ano tiveram uma natureza demonstrativa muito mais acentuada que no $2^{-}$ano, o que é grave, pois Barberá e Valdés (1996, p. 371) comentam que atividades pautadas nestas concepções são deficientes no aprendizado. Atualmente o que tem se buscado são metodologias que favoreçam a participação ativa do aluno e que permitam ao professor ser um auxiliador nesse processo de ensino/aprendizagem (SUART; MARCONDES, 2009, p. 52), o que está de acordo com a segunda opção.

De forma geral, tanto os alunos quanto os professores consideraram interessante e importante o uso de laboratório no processo ensino/aprendizagem. Além 


\section{Ensino, Saúde e Ambiente - V9 (2), pp. 63-93, Ago. 2016}

disso, principalmente os professores acreditam ser interessante materiais de apoio para facilitar a preparação de atividades desse tipo.

Assim sendo, partiu-se para a preparação dos materiais de apoio aos professores e alunos.

O caderno de apoio ao professor foi elaborado contendo orientações direcionadas para cada um dos três anos do EM do Colégio. Esse caderno teve 14 páginas e foi dividido em 10 seções com distintas finalidades.

A seção Primeiras palavras informa ao professor as novas ferramentas que podem ser usadas para promover o ensino e a aprendizagem de Química, além de ressaltar ao professor a importância do uso do laboratório, uma vez que o Colégio é um dos cerca de $11 \%$ dos colégios brasileiros que têm laboratório de ciências.

A seção O papel da experimentação no Ensino Médio apresenta os resultados de trabalhos que apontam como aplicar atividades laboratoriais na Educação Básica, e a metodologia a ser utilizada com os cadernos de experimentos propostos, como, por exemplo, a resolução do questionário pensando que existe no caderno de experimentos do aluno, e que tem o objetivo de ser um organizador prévio para o aluno. Ressalta-se também o papel socialmente ativo do professor durante a atividade experimental e a importância da alternância entre o empirismo e racionalismo. Por fim, são apresentadas as orientações quanto ao uso do caderno de conclusão do aluno e sua relevância na aprendizagem investigativa e no princípio da desaprendizagem.

A seção Organização das atividades experimentais apresentou o cronograma bimestral utilizado em 2013 considerando as 20 aulas de cinquenta minutos cada disponíveis no semestre. Esse dado serve como parâmetro para o professor programar suas atividades. Já na seção Necessidade de mudança no critério de avaliação há uma sugestão de instrumentos que poderão ser utilizados para obtenção da nota bimestral. Na seção Caderno de atividade experimental e o Currículo Mínimo foram organizados três quadros que mostram a correlação entre os conteúdos do programa de Química versus atividade experimental e a sugestão de conceitos que possam ser abordados para cada atividade experimental, embora ressaltamos que, como o professor tem liberdade de ação em sala de aula, ele deve abordar outros conceitos nessas atividades considerando sua experiência docente e o conhecimento de seus alunos.

A seção Periculosidade dos experimentos procura alertar o professor sobre os experimentos que devem ser realizados por ele ou com a sua participação para evitar acidentes. Na seção Rejeitos, foram consideradas questões como reutilização de material 


\section{Ensino, Saúde e Ambiente - V9 (2), pp. 63-93, Ago. 2016}

e produtos produzidos, uma vez que se pensou na importância de guardar o rejeito de íons cromo em local apropriado para depois reutilizá-lo e na combinação dos cátions e ânions que poderão ser dispostos em lixos ou rede de esgotos como a necessidade de ajuste do pH segundo Machado e Mól (p. 40, 2008b).

A seção Atividades artesanais apresenta quais são as atividades práticas que serão necessárias à construção de artefatos para a sua realização.

A confecção desse material está descrita em detalhes no caderno de experimentos do aluno quanto ao tipo de material necessário, assim como os procedimentos a serem realizados e pode estimular o aluno no processo de ensinoaprendizagem. A seção Caderno de conclusão apresenta a importância da atividade investigativa que, segundo Zômpero e Laburú (2011, p. 68):

“... possibilita o aprimoramento do raciocínio e das habilidades cognitivas dos alunos, e também a cooperação entre eles, além de possibilitar que compreendam a natureza do trabalho científico."

Nele o professor recebe informações básicas do que é a aprendizagem investigativa, o papel do professor no processo de ensino-aprendizagem do aluno e as diretrizes que os alunos deverão usar através dos conselhos dados pelos personagens Flint (tubo de ensaio), Sargento (proveta) e Carioca (balão de fundo redondo).

Em Considerações finais é informado que todas as sugestões apresentadas foram testadas anteriormente e que, apesar de desafiadoras, os resultados mostraram o desenvolvimento na aprendizagem crítica do aluno, um menor índice de reprovação e um maior interesse e motivação nas aulas de Química. Contudo, a seção finaliza deixando para o professor a escolha da metodologia que melhor lhe convém. O caderno apresenta as fontes de consulta na seção Referências bibliográficas.

O caderno de experimento dos alunos, elaborado no decorrer do ano de 2013, continha 50 atividades experimentais distribuídas de acordo com o conteúdo do Currículo Mínimo de Química do Estado do Rio de Janeiro para todos os anos do EM, e por essa razão foi produzido em três volumes para atender separadamente cada ano. $\mathrm{O}$ volume do $1^{\underline{0}}$ ano era contido de 57 páginas e 15 atividades experimentais, sendo 6 para serem desenvolvidas no $1^{\underline{o}}$ bimestre, 4 para o $2^{\underline{o}}, 2$ para o $3^{\underline{o}}$ e 3 para o $4^{\circ}$. O volume do $2^{\mathrm{o}}$ ano continha 74 páginas e 18 atividades experimentais, sendo 6 para serem desenvolvidas no $1^{\underline{o}}$ bimestre, 4 para o $2^{\underline{0}}, 3$ para o $3^{\circ}$ e 5 para o $4^{\underline{o}}$. Já o caderno do $3^{\circ}$ ano tinha 77 páginas e 17 atividades experimentais, sendo 5 para serem desenvolvidas no $1^{\circ}$ bimestre, 5 para o $2^{\circ}, 4$ para o $3^{\circ}$ e 3 para o $4^{\circ}$ bimestre. 
Os cadernos de experimentos foram divididos em seções com distintas funções que convergissem na busca da aprendizagem significativa crítica e investigativa.

A seção Para Refletir exibe pensamentos de diferentes autores que abordam uma reflexão política social. A função desses pensamentos é dual e foi inspirada em Paulo Freire (FREIRE, 2011a; FREIRE 2011b), procurando despertar no educador sua função humanista e revolucionária, em que sua ação com os educandos deve ser orientada no sentido da humanização de ambos, do pensar autêntico, da renuncia à manipulação, na transformação do mundo, na colaboração e na inserção crítica.

No tópico Apresentação, buscou-se de forma abrangente orientar o aluno quanto: ao tempo de cada aula prática; ao manuseio do caderno de experimentos e às funções a serem cumpridas por cada agente no processo de ensino-aprendizagem. $\mathrm{O}$ item $O$ Colégio e sua história foi inspirado nas orientações dos PCN e em Bachelard no que diz respeito à importância do uso da História no Ensino de Ciência e teve a colaboração de uma professora desse Colégio.

Em Normas de Segurança em Laboratório são traçadas as diretrizes para a realização das atividades experimentais nas quais são apresentados os equipamentos de proteção individual (EPI) e uma orientação de como devem ser usados.

Os três cadernos de experimentos do aluno teve quatro temas/conteúdos distintos que estão diretamente relacionados com os conceitos abordados nos quatro bimestres. Cada tópico possui uma introdução que interliga o cotidiano do discente com as atividades experimentais a serem realizadas, os quais foram divididos em quatro momentos baseados nos aportes teóricos de Moreira (2000) e epistemológicos de Bachelard (LOPES, 1993): pensando, agindo, concluindo e a Ciência dos cientistas.

Com o intuito de tornar as conclusões dos experimentos com perfil investigativo, resolveu-se elaborar em 2014 três cadernos de conclusão que desenvolvesse no alunado o interesse à pesquisa e ao levantamento de dados para o estudo de um tema, assim como os princípios apontados no caderno anterior. Deste modo, tanto o caderno de experimentos como o caderno de conclusão passaram a corroborar para o desenvolvimento do caráter investigativo e para a aprendizagem significativa crítica anterior e posterior à atividade experimental.

A seguir os materiais de apoio foram aplicados nos anos de 2013 e 2014, no Colégio, conforme descrito no percurso metodológico, visando a que o aluno inicie um desenvolvimento crítico e investigativo do seu aprendizado. 


\section{Ensino, Saúde e Ambiente - V9 (2), pp. 63-93, Ago. 2016}

As atividades experimentais em sala de aula foram realizadas em sua maioria em duplas, enquanto a conclusão final dos experimentos foi efetuada com a reunião de duas duplas que foram organizadas espontaneamente entre eles. Terminadas as aulas experimentais, os quartetos deveriam entregar suas conclusões finais em uma semana. $\mathrm{O}$ objetivo principal da reunião dos grupos foi promover o intercâmbio de ideias e significados das observações e conclusões prévias que cada dupla obteve no laboratório e provocar o que Bachelard chama de "turbulência na razão", ou seja, a necessidade de investigação desses dados, tomada de decisões/mudança na razão, a aprendizagem pelo erro/desaprendizagem e elaboração de novos modelos que representem melhor os fenômenos observados. Tais preceitos não são fáceis de serem atingidos, pois segundo Moreira (2000, p. 4):

“...a escola continua a não promover o 'aprender a aprender', pois ensina respostas certas, entidades isoladas, causas simples e identificáveis, transmissão do conhecimento, desestímulo do questionamento e conduz à ilusão da certeza."

Nesse sentido, o aluno pode não se adaptar de imediato a nova forma de aprender. Entretanto, pode ser interessante considerar esses objetivos para uma aula dinâmica e produtiva.

Após sua utilização, os 3 MA foram avaliados por quatro professores de Química do Colégio através de um questionário aplicado entre os dias 16 a 23 de outubro de 2014.

As quatro perguntas do questionário tratavam da avaliação pelos docentes do caderno de experimento do aluno, do caderno de conclusão do aluno e do caderno do professor. As três primeiras perguntas se dividiam em subperguntas de natureza objetiva e na quarta o professor poderia discursar com comentários e sugestões (Figura 3). 


\section{Ensino, Saúde e Ambiente - V9 (2), pp. 63-93, Ago. 2016}

Figura 3: Perguntas do questionário avaliativo dos professores.

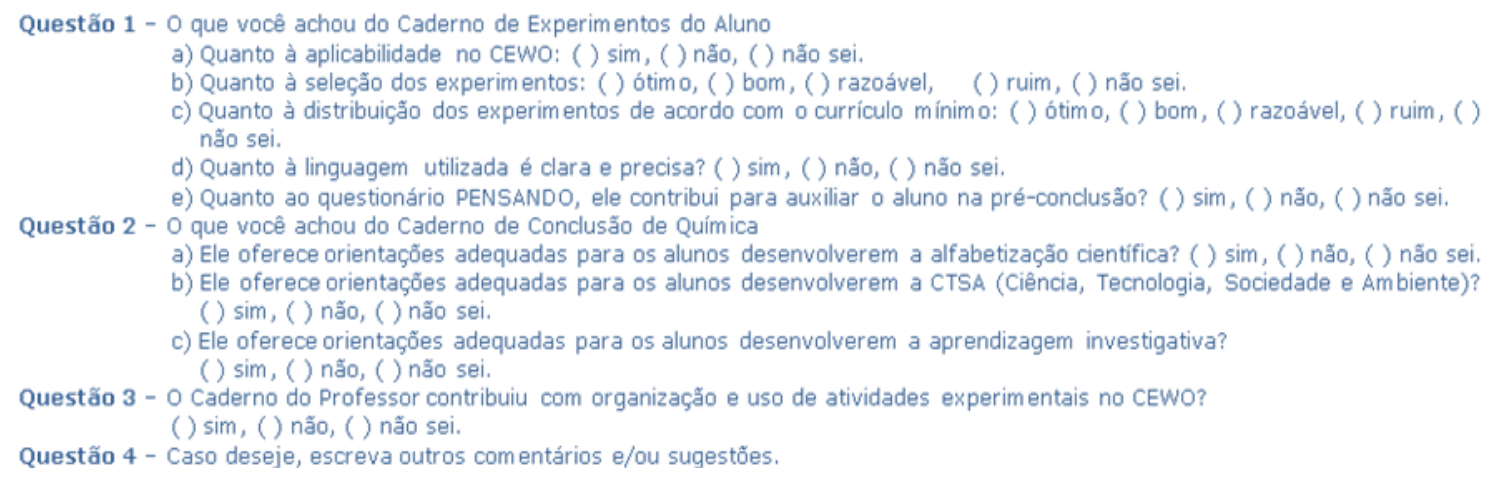

Fonte: Luciano Peres de Catro.

As respostas dos professores à primeira questão mostraram em todos os subitens uma avaliação $100 \%$ positiva. Deste modo, o problema apontado na diagnose (questão 6) realizada em outubro de 2012 foi solucionado, tendo em vista que os professores tinham respondido que a falta do caderno de experimentos era um dos principais fatores que impedia a realização de atividades práticas no Colégio.

Os resultados encontrados para todas as subperguntas da questão 2 foram "sim". Portanto, conclui-se que, na opinião dos professores, o caderno de conclusão contribui para observar o desenvolvimento das habilidades cognitivas dos alunos rumo à aprendizagem significativa crítica e possibilita o crescimento do pensamento científico para uma maior complexidade racional (MOREIRA; MASSONI, 2009, p. 29).

Nas respostas dos professores para a pergunta 3 observa-se o "sim" em 100\% delas, o que denota que todas as sugestões apontadas no caderno do professor poderão ser aplicadas no Colégio para a contribuição da melhoria do ensino-aprendizagem de Química.

Na pergunta 4, dois professores manifestaram comentários e sugestões. Um professor comentou que "todo o trabalho está formidável, entretanto o Caderno de Conclusão do Aluno está meio infantil apesar de bem esclarecedor", sugerindo a troca de algumas palavras, como galerinha por galera, em falas da história em quadrinhos contida no caderno, alegando que "no primeiro ano chamar os alunos de galerinha é formidável, mas para o segundo e terceiro anos já é mais adulto; aí só use o termo galera". O segundo professor parabenizou os materiais de apoio e o uso do lúdico nos personagens Flint, Carioca e Sargento existente nos cadernos dos alunos, pois seu uso torna as vidrarias do laboratório mais familiarizadas para os alunos. 


\section{Ensino, Saúde e Ambiente - V9 (2), pp. 63-93, Ago. 2016}

Apesar de o número de professores avaliadores não ser grande (4 professores), ele representa $100 \%$ dos professores de Química do turno diurno, o que demonstra uma avaliação positiva do material de apoio.

Além dos professores, os alunos avaliaram a infraestrutura do laboratório e os cadernos de experimentos nos dias 21 e 26 de novembro de 2013 com 227 alunos, para se observar sua contribuição no ensino/aprendizagem dos alunos, a fim de que pudesse ser melhorado para 2014.

O questionário possuía 6 perguntas-chaves que se dividiam em subperguntas de diferentes naturezas com opções de múltipla escolha. Da primeira a terceira pergunta, havia duas subperguntas de natureza discursiva em que o entrevistado poderia fazer comentários ou dar sugestões. Na terceira pergunta para as turmas do segundo e terceiro anos houve um acréscimo de duas subperguntas que tratam da confecção das atividades artesanais. A Figura 4 mostra as 3 primeiras questões do questionário avaliativo dos alunos.

\section{Figura 4. Perguntas 1 a 3 do questionário avaliativo dos alunos}

Questão 1-o que você achou do laboratório

a) Quanto à limpeza: ( ) ótimo, ( ) bom, ( ) razoável, ( ) ruim, ( ) não sei.

b) Quanto à iluminação: ( ) ótimo, ( ) bom, ( ) razoável, ( ) ruim, ( ) não sei.

c) Quanto à disponibilidade dos reagentes: () ótimo, ( ) bom, ( ) razoável, () ruim, () não sei.

d) Quanto à disponibilidade das vidrarias: ( ) ótimo, () bom, ( ) razoável, ( ) ruim, () não sei.

e) Quanto ao seu espaço e comodidade: () ótimo, ( ) bom, () razoável, ( ) ruim, () não sei.

f) Se tiver algum comentário escreva abaixo.

g) Se tiver alguma sugestão escreva abaixo

Questão 2: 0 que você achou dos experimentos

a) Quanto à clareza: ( ) ótimo, ( ) bom, () razoável, ( ) ruim, ( ) não sei.

b) Quantoà realização: ( ) ótimo, ( ) bom, ( ) razoável, ( ) ruim, ( ) não sei.

c) Quanto à periculosidade: () muito perigoso, ( ) perigoso, ( ) pouco perigoso, ( ) sem perigo, ( ) não sei.

d) Quanto estar vinculado às aulas teóricas: ( ) ótimo, ( ) bom, () razoável, ( ) ruim, () não sei.

e) Quanto ao interesse: ( ) ótimo, ( ) bom, ( ) razoável, ( ) ruim, ( ) não sei.

f) Qual experimento que você mais gostou?

g) Se tiver algum comentário escreva abaixo.

h) Se tiver alguma sugestão escreva abaixo.

Questão 3: Com relação ao Caderno de Experimentos

a) Fazer o PENSANDO foi útil para auxiliar na conclusão dos experimentos? ( ) sim, ( ) não, ( ) não sei.

b) Os experimentos estavam bem escritos? () sim, () não, () não sei.

c) Ela é útil e poderá ser aplicada a todas as turmas de quimica da escola? ( ) sim, ( ) não, ( ) não sei.

d) Ela está bem organizada? ( ) sim, ( ) não, ( ) não sei.

e) As figuras e fotos estão bem feitas? ( ) sim, ( ) não, ( ) não sei.

f) Ela te auxiliou na melhor compreensão da teoria? () sim, ( ) não, ( ) não sei.

g) Os equipamentos que foram construídos por você como condutor de corrente elétrica e chuva ácida estavam

bem escritos? ( ) sim, ( ) não, ( ) não sei.

h) As fotos usadas como instrução para montagem dos equipamentos foram úteis? ( ) sim, ( ) não, ( ) não sei.

i) Se tiver algum comentário escreva abaixo.

j) Se tiver alguma sugestão escreva abaixo.

\section{Fonte: Luciano Peres de Castro}

As respostas para alguns questionamentos das perguntas 1 a 3 estão apresentadas na Figura 5. 


\section{Ensino, Saúde e Ambiente - V9 (2), pp. 63-93, Ago. 2016}

Figura 5. Respostas das questões 1 a 3 do questionário avaliativo dos alunos
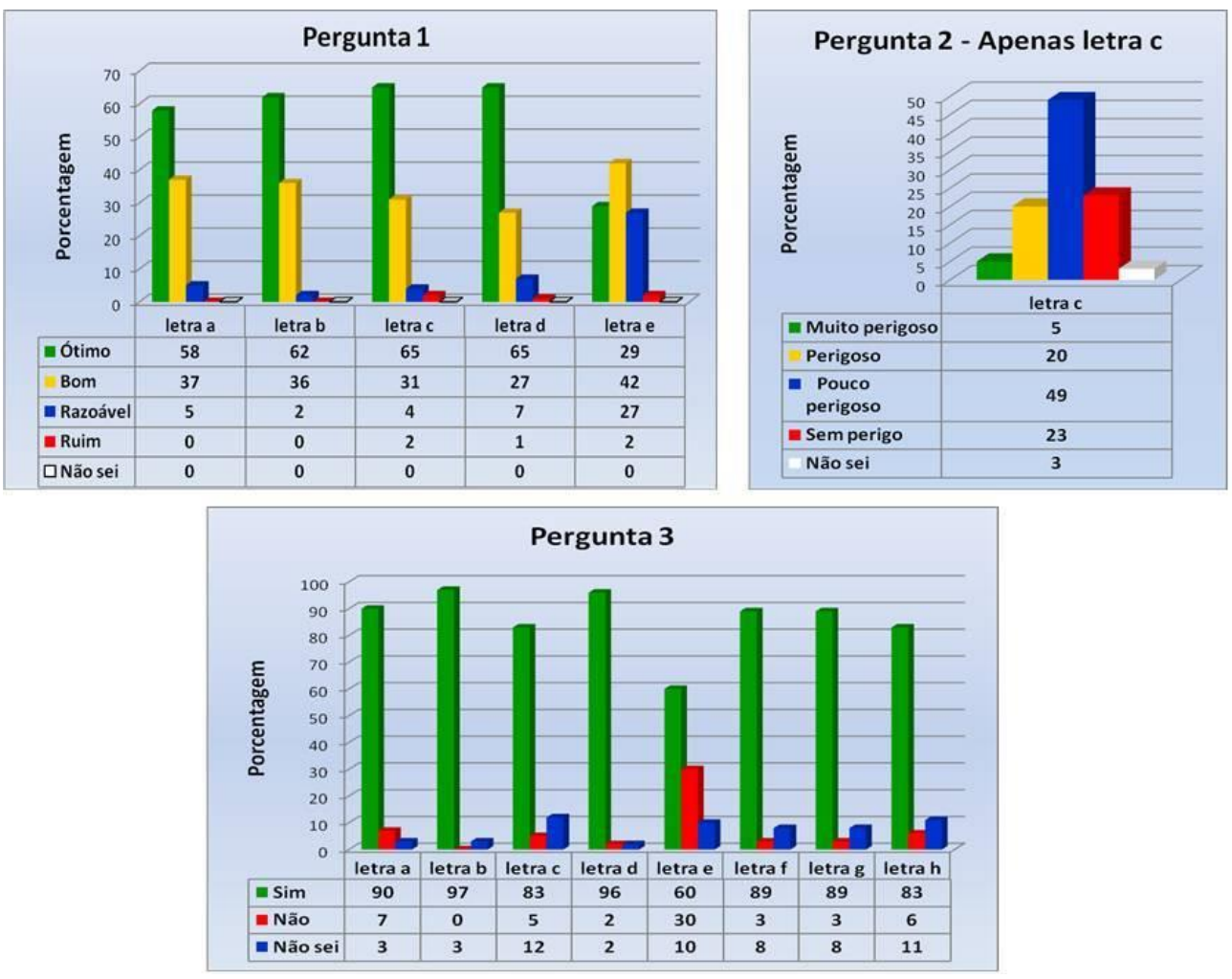

Fonte: Luciano Peres de Castro

O laboratório teve uma avaliação positiva salvo o item referente ao espaço e comodidade, tendo em vista que nos comentários o desconforto dos bancos e o tamanho da bancada em relação ao número de alunos foram as causas para o resultado negativo. Os alunos ainda sugeriram uma melhoria do arejamento e da luminosidade. Os experimentos tiveram uma avaliação positiva, salvo a questão da clareza. Os comentários foram: deveriam ser realizados mais experimentos; as aulas práticas fazem compreender melhor as aulas teóricas; deveriam ser dadas mais aulas teóricas para compreendermos a prática; o pensando deu base para compreender a prática; os experimentos efeito estufa, chuva ácida e perigo, não fume são muito criativos. Foi sugerido que se aumentasse a quantidade de aulas teóricas e práticas.

Através dos comentários e sugestões dos alunos, a conclusão preliminar é que a dificuldade de compreender os experimentos está em função da necessidade do aumento de números de aulas teóricas e práticas. Esse fato mostra que a mudança de paradigma do modelo de uma escola tradicional para um modelo baseado na aprendizagem significativa crítica, em que os alunos são desafiados a questionar, pensar, refletir, buscar explicações, testar suas hipóteses e expor oralmente o novo conhecimento com os conhecimentos prévios é um trabalho lento, mas necessário.

Os experimentos mais votados em ordem crescente de interesse foram: 
a) $1^{\circ}$ ano - "é falso ou verdadeiro", "cromatografia em papel”, "bicarbonato de sódio em vinagre", "queima da vela", "que mistério é esse", "foguete a álcool comercial", "densidade dos metais", "teste em chama" e "afinal é cromato ou dicromato";

b) $2^{\circ}$ ano - "testando os indicadores", “chuva ácida”, "bolinha mágica", "verificando as reações", "efeito estufa", "pasta de dente de elefante", "varinha mágica", "conduz ou não e perigo", "não fume";

c) $3^{\circ}$ ano - "reatividade dos metais", "pilha de refrigerante", "tem proteína", “o poder está nas mãos”, “vamos fazer sabão", "eletrólise”, "pilha de batata”, “aplicando a lei 12.760/12" e "Kabum".

O Caderno de Experimentos foi bem aceito pelos alunos da escola. Quanto à natureza das figuras e fotos, $30 \%$ dos entrevistados responderam negativamente. Os comentários e sugestões que trataram especificamente do problema relataram que as fotos na cópia estavam escuras e se não poderiam ser coloridas. Para resolver esse problema, foi sugerido a disponibilização dos arquivos no formato pdf na biblioteca da escola para que os discentes utilizem em seus celulares ou computador pessoal. Houve também um único comentário dentre os 227 alunos dizendo que "as atividades experimentais não estão de acordo com o conteúdo teórico dado em sala de aula”.

Outras sugestões descritas foram: as atividades experimentais deveriam ser realizadas desde o primeiro ano; o laboratório deveria ser utilizado por todos os professores de Química para aumentar o interesse e o entendimento; colocar um espaço após o questionário pensando destinado às respostas. Ressaltamos que, em relação à última sugestão, no caderno de atividades experimentais de 2014 foi acrescentado um espaço para as respostas do questionário pensando.

As questões 4 a 6 procuraram perceber a motivação dos alunos quanto à experimentação, a influência das aulas experimentais em outras disciplinas, e se contribuíram para provas e exames externos ao colégio, tendo em vista que muitos alunos estavam fazendo exames de ENEM, dentre outros. A Figura 6 mostra as perguntas 4 a 6 . 


\section{Ensino, Saúde e Ambiente - V9 (2), pp. 63-93, Ago. 2016}

Figura 6. Perguntas 4 a 6 do questionário avaliativo dos alunos

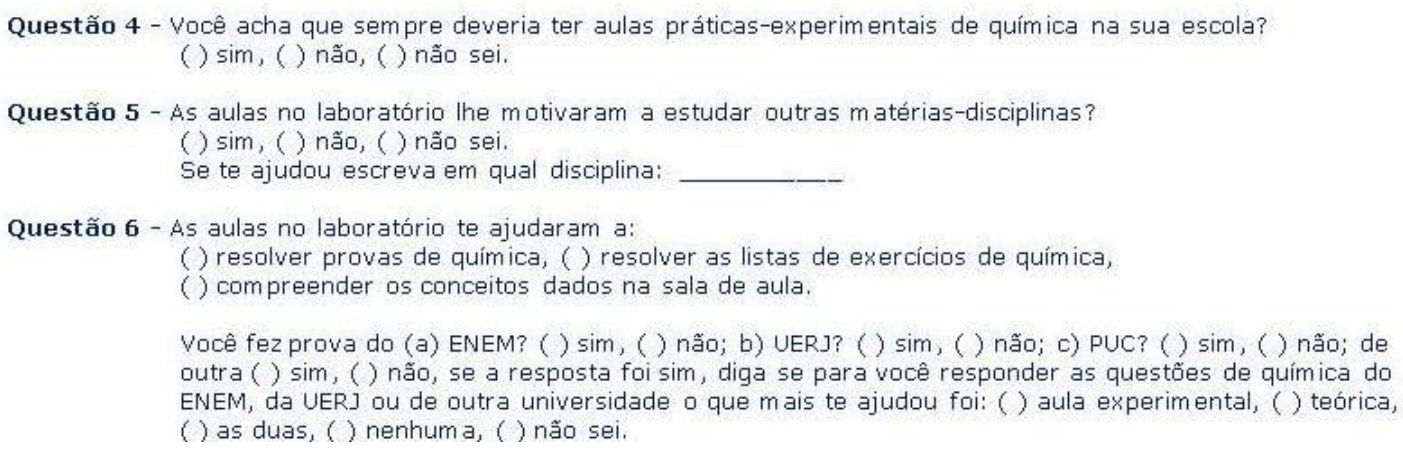

\section{Fonte: Luciano Peres de Castro}

Em relação à pergunta 4, a maioria dos alunos, 79\% deles disseram sim, 15\% não e $6 \%$ não sei. A aprovação pela experimentação, talvez mostre que a proposta desse trabalho que está baseada nos aportes teóricos e epistemológicos de Moreira e Bachelard possa ser adotada nas aulas laboratoriais de Química do colégio. Os 15\% dos alunos que responderam não deveriam ter aulas experimentais está correspondendo àqueles que responderam de forma negativa na questão $2 \mathrm{a}$, onde se percebe que a falta de compreensão dos experimentos e a pré-disposição do sujeito para aprender podem ter sido um dos fatores que influenciaram na rejeição da continuidade do projeto.

Quanto à pergunta 5, os alunos consideraram na sua maioria que as aulas experimentais não os motivaram a se dedicar mais em outras disciplinas, tendo em vista que apenas $16 \%$ disseram sim, enquanto $75 \%$ marcaram não e $9 \%$ não sei. Entretanto, dos que disseram sim, as disciplinas mais votadas em ordem crescente foram: matemática, física e biologia. Apesar de o saldo positivo ter sido baixo, ele é expressivo pelo fato dos experimentos de Química influenciarem no interesse de outras disciplinas. A maior motivação ocorreu nas disciplinas de Física e Biologia, o que aponta a necessidade de união das ciências da natureza em atividades de laboratório para a melhoria da qualidade do ensino e aprendizagem.

Em relação à pergunta 6 , sobre a influência da experimentação para compreender os conceitos teóricos, o que evidencia a conciliação entre teoria e práxis, a nova experiência disse não à experiência antiga e, assim, avança o pensamento científico, visto que 54\% dos alunos disseram que ajudou a compreender conceitos, $22 \%$ a resolver lista de exercícios e $24 \%$ a resolver provas. Esse resultado mostra que a experimentação contribuiu para a reflexão dos alunos sobre a importância do raciocínio em detrimento de resolver listas de exercícios e provas. Das respostas à questão 6, ainda podemos dizer que 53 alunos dos 113 prestaram vestibulares ou outro tipo de concurso. 


\section{Ensino, Saúde e Ambiente - V9 (2), pp. 63-93, Ago. 2016}

A preferência dos concursos prestados em ordem crescente foi: Marinha do Brasil, IBEMEC, PUC, CEDERJ, UERJ e ENEM. Desse quantitativo, 62\% marcaram as duas (aulas teóricas e experimentais), 22\% aula teórica, 15\% aula experimental e 1\% não sei. Mais uma vez o resultado corrobora com a premissa Bachelardiana de que a conciliação entre teoria e práxis avança o pensamento científico.

Uma breve percepção da influência do material de apoio desenvolvido no aprendizado dos alunos foi realizada usando uma análise comparativa do índice aprovação/reprovação entre os anos de 2012 e 2013, ano que não usou a metodologia (2012) e ano que a utilizou (2013), e a análise das conclusões das atividades experimentais obtidas a partir do caderno de conclusão dos alunos.

Lembramos que os instrumentos utilizados para avaliar os alunos em 2012 foram: a) comportamento e presença com peso 1; b) teste com peso 3; c) SAERJ com peso 0,5 ; e d) prova com peso 5,5. Além disso, houve apenas uma mudança no tipo de avaliação entre os dois anos, a nota de comportamento e presença utilizada em 2012 foi substituída pelo questionário PENSANDO em 2013, e o teste/trabalho em dupla foi substituído pelas conclusões dos experimentos. Ressalta-se que a avaliação no Ensino Básico é contemplada nos itens V, VI e VII, do artigo 24 da LDB. O item V frisa que o "rendimento escolar observará o critério de uma avaliação contínua e cumulativa do desempenho do aluno, com prevalência dos aspectos qualitativos sobre os quantitativos e dos resultados ao longo do período sobre os de eventuais provas finais". As provas de 2012 e 2013 foram objetivas, conforme orientações do Colégio, baseados em questões de exames de vestibulares do Estado do Rio de Janeiro ou do ENEM.

$\mathrm{Na}$ primeira percepção do aprendizado dos alunos se comparou o índice aprovação/reprovação entre o ano 2012 e 2013. Nesse caso, a reprovação caiu 14\% com a mudança de alguns instrumentos de avaliação, o que é um saldo muito positivo partindo da ideia que o modelo tradicional que forma um aluno passivo, receptor/retentor dos conteúdos e sem criticidade da realidade que o cerca, foi substituído por um modelo inovador no qual o aluno é ativo, explorador, racionaliza e cria modelos e se apropria da compreensão dos conteúdos da aprendizagem. Conclui-se também que as mudanças dos instrumentos de avaliação permitiram a melhoria do aprendizado dos alunos da escola ou no mínimo a motivação, e esse diagnóstico indica a importância da experimentação como um agente auxiliador/transformador no ensino/aprendizagem. 


\section{Ensino, Saúde e Ambiente - V9 (2), pp. 63-93, Ago. 2016}

A segunda percepção do aprendizado deu-se em 2013 e 2014 através da análise dos comentários feitos pelos alunos nos cadernos de conclusões e notou-se de modo geral que o alunado possui dificuldade em expressar o pensamento em palavras, demonstrando que escrever não é um hábito comum entre eles. Apesar dessas prerrogativas estarem mais direcionadas aos professores de Língua Portuguesa, a aprendizagem significativa crítica traz como pressuposto que o aluno é um perceptor/representador do mundo e representará o conhecimento através da linguagem escrita. Considerando que os alunos desse Colégio estão inseridos em uma escola tradicional, ao analisar as conclusões encontradas no caderno de conclusão dos alunos, constatou-se a percepção na aprendizagem significativa crítica. A Figura 7 mostra algumas anotações retiradas de alguns cadernos de conclusão, nas quais é possível perceber comentários que demonstram certa maturidade crítica/reflexiva. Esse fato demonstra que desenvolver no alunado o despertar para a reflexão e a crítica com a colaboração do uso do material de apoio desenvolvido pode ser conseguido.

Figura 7. Anotações nos cadernos de conclusão dos alunos.
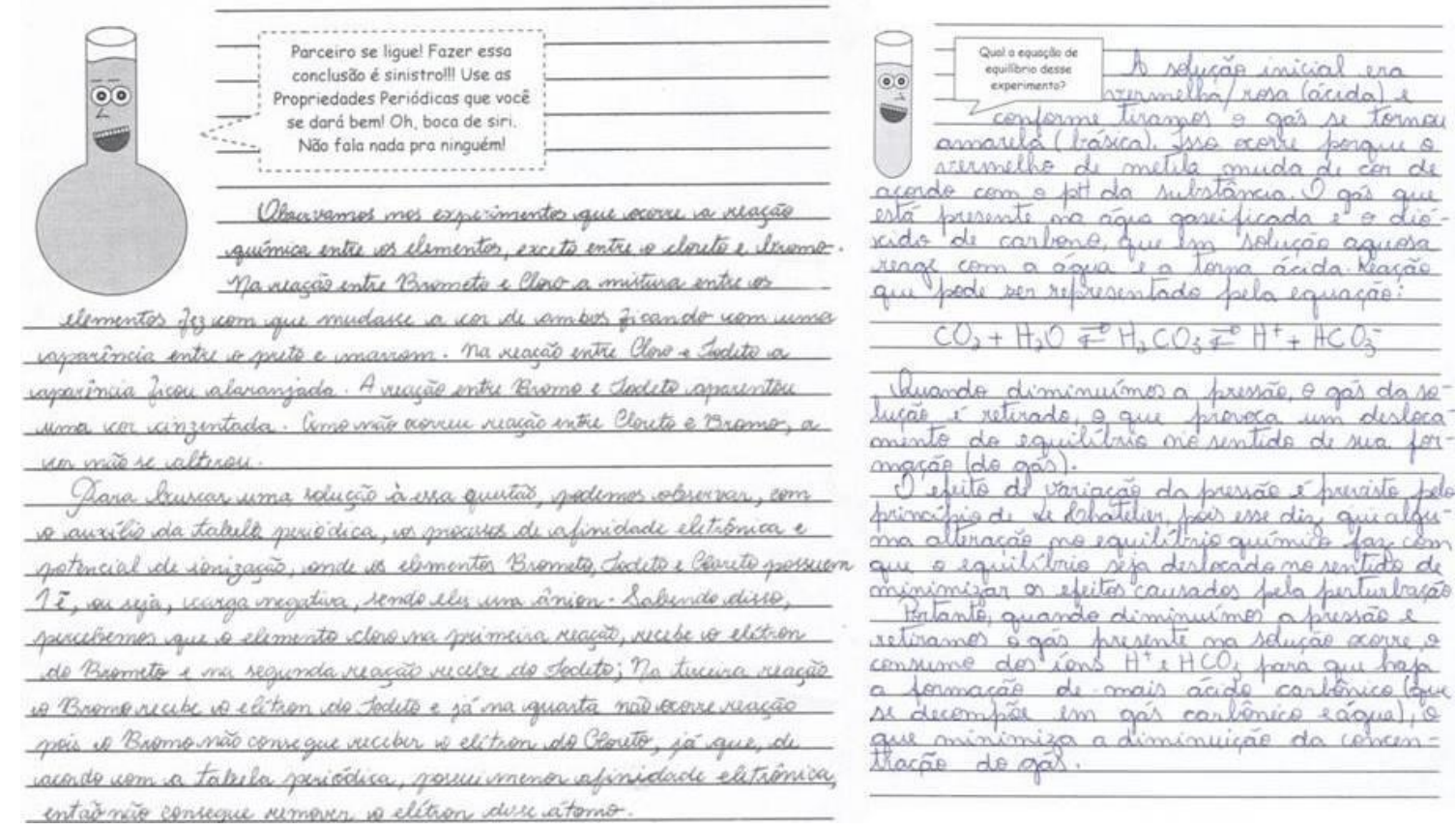

Fonte: Luciano Peres de Castro.

\section{CONCLUSÃO}

Através de questionários diagnósticos sobre a utilização do laboratório do Colégio, os quais foram respondidos por professores e alunos, constatou-se: a) sua pouca utilização; b) falta de material de apoio para professor e aluno; c) falta de 


\section{Ensino, Saúde e Ambiente - V9 (2), pp. 63-93, Ago. 2016}

monitor; d) excesso de alunos; e) poucas aulas de Química; f) atividades experimentais com natureza demonstrativa.

Os cadernos de experimentos dos alunos foram escritos de forma simples, procurando a autonomia do aluno nas atividades laboratoriais para que o professor tivesse liberdade de ação, desenvolvesse a aprendizagem entre pares e tornasse o ensino socialmente ativo. O caderno do primeiro ano tem 57 páginas e 15 atividades experimentais, o do segundo ano 74 páginas e 18 atividades experimentais e o do terceiro ano tem 77 páginas e 17 atividades experimentais. As atividades laboratoriais foram desenvolvidas no tripé pensar, agir e concluir.

A aplicação dos experimentos usando os cadernos de atividades experimentais deu-se com 227 alunos em 2013 e 223 alunos em 2014. Os grupos de trabalho foram organizados em duplas de alunos durante as atividades práticas, e observou-se que houve dificuldades no desenvolvimento da aprendizagem investigativa nos períodos iniciais, mas esse quadro foi alterado para melhor nos momentos seguintes, o que corrobora a ideia de que essa metodologia pode ser usada para melhorar o aprendizado.

O caderno de conclusão dos alunos foi elaborado para os três anos do EM, buscando o desenvolvimento da aprendizagem investigativa e crítica pós-atividade experimental, buscando as implicações CTSA do estudo realizado, a alfabetização científica e a leitura de novas fontes de informação.

Os professores de Química do turno diurno avaliaram os cadernos de apoio dos alunos (caderno de experimentos e conclusão) e o caderno de professores e consideraram de forma positiva o trabalho desenvolvido.

Os cadernos de atividades experimentais também foram avaliados por 227 alunos que participaram das atividades experimentais em 2013, os quais foram aprovados pela maioria dos alunos. Entretanto, por intermédio de algumas sugestões os cadernos foram melhorados e aplicados em 2014. Essas atitudes demonstram a importância de se dialogar com os alunos para a melhoria do processo ensino/aprendizagem.

Uma breve percepção da contribuição dos materiais de apoio na aprendizagem dos alunos foi realizada, comparando-se o índice de aprovação dos 221 alunos do ano de 2012, ano em que não foi aplicada a metodologia desenvolvida, e dos 227 alunos do ano de 2013, ano em que os materiais de apoio foram usados, bem como ao se analisar as anotações dos alunos registradas em seus cadernos de conclusão. Dessas análises podemos considerar de forma geral que houve uma melhoria no índice de aprovação, 
assim como na melhoria da escrita e comunicação dos alunos, uma vez que os textos estavam mais elaborados. Esse fato demonstra que, ao se utilizar os materiais de apoio, os alunos se mostraram mais dispostos à discussão e investigação, o que deve ter proporcionado uma melhoria e/ou motivação no aprendizado.

Esperamos que, com os materiais de apoio desenvolvidos nesse trabalho, a experimentação possa ser uma ferramenta importante para a aprendizagem significativa de Química do alunado, e que atinja o desejo de alunos e professores desse colégio em ter mais um recurso importante no seu desenvolvimento crítico-investigativo ao usar o laboratório construído com tanta dedicação por antigos colaboradores/professores.

\section{AGRADECIMENTOS}

Agradecemos em especial à Professora Marlene Cunha pelo incentivo.

\section{REFERÊNCIAS BIBLIOGRÁFICAS}

ABREU, E.S. A formação do espírito científico: contribuição para uma psicanálise do conhecimento/Gaston Bachelard. Rio de Janeiro: Contraponto, 2011.

BARBERÁ, O.; VALDÉS, P. El trabajo práctico la enseñanza de lãs ciências: una revision. Enseñanza de las Ciencias. v.14, n.3, p. 365-379, 1996.

BRASIL. LEI DE DIRETRIZES E BASES DA EDUCAÇÃO NACIONAL: Lei 9.394 de 1996. Disponível em: 〈http://www.planalto.gov.br/ccivil_03/leis/L9394.htm>. Acessado em junho 2016.

BRASIL. SECRETARIA DE EDUCAÇÃO MÉDIA E TECNOLÓGICA. PARÂMETROS CURRICULARES NACIONAIS: MEC/SEMTEC, 2002.

BUENO, R.S de M.; KOVALICZN, R.A. O Ensino de Ciências e as dificuldades das atividades experimentais. Disponível em:

$<$ http://www.diaadiaeducacao.pr.gov.br/portals/pde/arquivos/23-4.pdf > Acessado em junho 2016.

CÂMARA, N.S. Análise comparativa entre o livro didático e a apostila. Anais do SIELP, Uberlândia: EDUFU, v. 2, n. 1, 2012. Disponível em:

$<$ http://www.ileel.ufu.br/anaisdosielp/wpcontent/uploads/2014/07/volume_2_artigo_239.pdf> Acessado em maio de 2016.

CHASSOT, A. Alfabetização científica: uma possibilidade para a inclusão social. Revista Brasileira de Educação. v. 22, 89 100, 2003. 
FARIAS, C.S.; BASAGLIA, A.M.; ZIMMERMANN, A. A importância das atividades experimentais no Ensino de Química. Anais do $1^{\circ}$ Congresso Paranaense de Educação em Química: Paraná, 2009. Disponível em:

<http://www.uel.br/eventos/cpequi/Completospagina/18274953820090622.pdf.>

Acessado 5 de maio de 2016.

FRANCISCO JR., W.E.; FERREIRA, L.H.; HARTWIG, D.R. Experimentação

Problematizadora: Fundamentos Teóricos e Práticos para a Aplicação em Salas de Aula de Ciências. Química Nova na Escola. v. 30, p. 34- 41, 2008.

FREIRE, P. (a). Pedagogia do oprimido. Rio de Janeiro: Paz e Terra, 2011.

FREIRE, P. (b). Pedagogia da autonomia, saberes necessários à prática educativa. Rio de Janeiro: Paz e Terra, 2011.

GUIMARÃES, C.C. Experimentação no Ensino de Química: Caminhos e Descaminhos Rumo à Aprendizagem Significativa. Química Nova na Escola, v. 31, n. 3, p. 198202, 2009.

GIORDAN, M. O Papel da Experimentação no Ensino de Ciências. Química Nova na Escola. v. 10, p. 43 49, 1999.

KAUARK, F. da S.; MANHÃES, F.C.; MEDEIROS, C.H. Metodologia da Pesquisa um guia prático. Bahia: Editora Via Litterarum, 2010.

LAJOLO, M.; ZILBERMAN, R. A formação da leitura no Brasil. São Paulo: Editora Ática, 1996.

LIMA, R. de. Escola apostilada: ilusão ou barbárie? Revista Espaço Acadêmico. n. 63, ago. 2006. Disponível em: <http://www.espacoacademico.com.br/063/63lima.htm>.

Acessado em maio de 20016.

LOPES, A.R.C. Bachelard: O filósofo da Desilusão. Caderno Brasileiro de Ensino de Física, v. 13, n. 3, p. 248-273, dez., 1996.

LOPES, A.R.C. Contribuições de Gaston Bachelard ao Ensino de Ciências. Enseñanza de Las Ciencias. v. 11, n 3, p. 324- 330, 1993.

MACHADO, P.F.L.; MÓL, G. de S. Experimentando a Química com Segurança. Química Nova na Escola. v. 27, p. 57 -60, 2008.

_ b. Resíduo e rejeitos de aulas experimentais: o que fazer? Química Nova na Escola, v. 29, p. $3841,2008$.

MALDANER, O.A. A formação inicial e continuada de professores de Química. Ijuí: Unijuí, 2003.

MOREIRA, M.A. Aprendizagem significativa crítica. Porto Alegre: UFRGS, 2000. 
MOREIRA, M.A.; MASSONI, N.T. Subsídios Epistemológicos para Professor Pesquisador em Ensino de Ciências: Epistemologia do século XX. Porto Alegre: UFRGS, 2009.

OLIVEIRA, R.C. de, HARTING, D.R.; FERREIRA, L.H. Ensino Experimental de Química: Uma abordagem Investigativa Contextualizada. Química Nova na Escola. v. 32, n. 2, p. 101- 106, 2010.

PACHECO, L.R.E.; COELHO, C.F. O material didático impresso como facilitador na educação a distância. Simpósio Internacional de Educação a Distância, 2012. <Disponível em: http://sistemas3.sead.ufscar.br/ojs/Trabalhos/220-782-1-ED.pdf.> Acessado em maio de 2016.

RIO DE JANEIRO (2012). Currículo Mínimo de Química. Rio de Janeiro: Secretaria de Estado de Educação do Rio de Janeiro, 2012. Disponível em: $<$ http://www.rj.gov.br/web/seeduc/exibeconteudo?article-id=759820>. Acessado em junho $2016 .$.

SANTOS JR, J.B. do; MARCONDES, M.E.R. Experimentação no ensino: uma investigação sobre as concepções de um grupo de professores de Química de escolas públicas de São Paulo. XV ENEQ, 2010. Disponível em:

<http://www.xveneq2010.unb.br/resumos/R0697-1.pdf>. Acessado em maio de 2016.

SANTOS, W.L.P; SCHNETZIER, R.P. Função Social: O que significa ensino de química para formar o cidadão? Química Nova na Escola. v. 4, p. 28- 34, 1996.

SUART, R. de C.; MARCONDES, M.E.R. A manifestação de habilidades cognitivas em atividades experimentais investigativas no ensino médio de química. Ciências \& Cognição. v. 14, n 1, p. 50- 74, 2009.

SUART, R. de C.; MARCONDES, M.E.R.; LAMAS, M.F.P. A estratégia "Laboratório Aberto" para a construção do conceito de temperatura de ebulição e a manifestação de habilidades cognitivas. Química Nova. v. 32, n. 3, p. 200 207, 2010.

ZÔMPERO, A.F.; LABURÚ, C.E. Atividades investigativas no ensino de ciências: aspectos históricos e diferentes abordagens. Revista Ensaio. v. 3, n. 3, p. 67- 80, 2011. 